\title{
Terapias regenerativas em implantodontia: avanços no uso da Fibrina rica em plaquetas (PRF)
}

Regenerative therapies in implant dentistry: advances in application of platelet rich fibrin (PRF)

Terapias regenerativas en implantología: avances en el uso de fibrina rica en plaquetas (PRF)

Carolina Chaves Gama Aires ${ }^{1 *}$, Eugênia Leal De Figueiredo ${ }^{1}$, Vinícius Balan Santos Pereira ${ }^{1}$, Ricardo José De Holanda Vasconcellos ${ }^{1}$, Maria Eduarda Bené De Oliveira Sabino ${ }^{1}$ e Marcelo Farias De Medeiros.

\section{RESUMO}

Objetivo: realizar uma análise a respeito do uso da fibrina rica em plaquetas (PRF) na Implantodontia nos últimos 10 anos, suas aplicações, vantagens e limitações da técnica, mudanças de protocolo e visando incrementar a prática clínica dos cirurgiões-dentistas. Revisão bibliográfica: A fibrina rica em plaquetas (PRF), é um aditivo biológico derivado da centrifugação de uma amostra sanguínea do paciente, e vem sendo usado de várias formas na Odontologia. Na Implantodontia, os estudos vêm focando no potencial do PRF em acelerar a osseointegração, na preservação de rebordos alveolares após exodontias, bem como no aumento dos rebordos e reparo de defeitos periimplantares. Nos levantamentos de seios maxilares, o PRF demonstra ser um material versátil e seguro, além de possibilitar uma redução de custos associados aos biomaterias. Considerações finais: os estudos são promissores e apontam para avanços e ganhos nas regenerações teciduais associados ao emprego do PRF, apesar da necessidade de mais ensaios clínicos para comprovar os resultados positivos encontrados nos estudos pré-clínicos.

Palavras-chave: Fibrina rica em plaquetas, Regeneração óssea, Implantes dentários.

\section{ABSTRACT}

Objective: to analyze the applications of platelet-rich fibrin (PRF) in implant denstistry over the last 10 years. Use of PRF, protocol changes, advantages and limitations of technique in order to increase the clinical practice of dentists. Literature review: Platelet rich fibrin (PRF), as a biological additive obtained from the centrifugation of a patient's blood sample, has been used in several techniques with different purposes. In implant dentistry, studies have focused on the potential of PRF to accelerate osseointegration, preservation of alveolar ridges after extraction, as well as the augumentation and repair of peri-implant defects. In sinus floor elevation procedure, PRF has been shown to be a versatile and safe material, besides reduce costs associated with biomaterials. Final considerations: The studies are promising and point to gains in bone and soft tissue regeneration associated with the use of PRF. However, clinical trials are need to prove the positive results found in preclinical studies.

Key words: Platelet-rich fibrin, Bone regeneration, Dental implants.

${ }_{1}^{1}$ Faculdade de Odontologia de Pernambuco - Universidade De Pernambuco (FOP/UPE), Camaragibe - PE.

*E-mail: carol20101@gmail.com.

2 Centro de Pós-graduação em Odontologia (CPGO) Recife- PE. 


\section{RESUMEN}

Objetivo: realizar un análisis a cerca de el uso de fibrina rica en plaquetas (PRF) en implantología en los últimos 10 años, sus aplicaciones, ventajas y limitaciones de la técnica, cambios de protocolo y com um propósito de aumentar la práctica clínica de los dentistas. Revisión bibliográfica: El fibrina rica em plaquetas (PRF), como aditivo biologico obtenido de la centrifugación de una muestra de sangre de un paciente, se ha utilizado de diversas maneras en odontología. En implantología, los estudios se han centrado en el potencial de PRF para acelerar la osteointegración, la preservación de las crestas alveolares después de la exodoncia, así como la ampliación de los reborde alveolares y reparación de defectos periimplantarios. En el levantamiento de senos maxilares, el PRF se ha demostrado un material versátil y seguro, además de permitir una reducción de costos asociados con biomateriales. Consideraciones finales: Los estudios son prometedores y apuntan a avances y ganancias en la regeneración de tejidos asociados con el uso de PRF, a pesar de la necesidad de más ensayos clínicos para demostrar los resultados positivos encontrados en los estudios preclínicos.

Palabras clave: Fibrina rica en plaquetas, regeneración ósea, implantes dentales.

\section{INTRODUÇÃO}

Existem muitas razões para as atrofias dos maxilares, sendo a perda dentária, um fator primordial. A reabsorção óssea é mais pronunciada no primeiro ano após as exodontias, porém tem um caráter contínuo e progressivo por toda a vida. A atrofia dos rebordos geralmente é associada a dificuldades na instalação de próteses convencionais, bem como nas próteses sobre implantes (CHENCHEV IL, et al., 2017).

Sendo assim, a atrofia dos rebordos alveolares é uma condição clínica que requer uma série de cuidados e procedimentos que visam incrementar o potencial de ganho tecidual nas regiões afetadas. $O$ uso de biomateriais com o objetivo de substituir as deficiências ósseas nas regiões a serem implantadas devem fornecer uma boa resposta biomecânica às cargas mastigatórias, uma ótima capacidade de estimular/repor tecido ósseo, bem como tornar as estruturas neoformadas funcionais (TATULLO M, et al., 2012).

A fibrina rica em plaquetas (PRF) faz parte da segunda geração dos concentrados plaquetários e vem sendo clinicamente usados com a intenção de acelerar a reparação tecidual e a regeneração óssea. O PRF faz parte da segunda geração de concentrados plaquetários e foi descrito pela primeira vez em 2001 na França por Choukron. É obtido a partir de uma amostra sanguínea, do próprio paciente, sem adição de nenhum anticoagulante ou ativadores como a heparina, por exemplo, e levado a centrifugação para obter os elementos que podem ser úteis para melhorar a cura e promover a regeneração tecidual (ÖNCU E, et al., 2016; TATULLO M, et al., 2012; CANELLAS JVDS, et al., 2018; AGRAWAL AA, et al., 2017).

Esse concentrado tende a ser mais eficiente, do ponto de vista biológico, que os predecessores, a exemplo do plasma rico em plaquetas (PRP). Ao contrário de outros concentrados de plaquetas, o PRF não se dissolve rapidamente após a aplicação, as plaquetas e leucócitos são coletados com alta eficiência, por isso também sendo conhecido como L-PRF, e as plaquetas são ativadas durante o processo, levando a incorporação de fatores de crescimento e leucócitos na matriz de fibrina (ALI S, et al., 2015).

Pesquisas usando membranas de PRF tem indicado a aceleração dos processos de regeneração óssea e de tecidos moles, bem como a sua aplicação nas cirurgias reconstrutivas. É nesse contexto que as pesquisas acerca dos materiais capazes de acelerar e promover a regeneração tecidual, como o PRF, recebem grande atenção do mundo científico e vem sendo alvo de inúmeros estudos (HARTLEV J, et al., 2019). Estudos nessa área são fundamentais para a compreensão dos processos biológicos envolvidos e a aplicabilidade desse material (SHAH R, et al., 2017).

Sendo assim, o objetivo do presente estudo é fazer uma análise a respeito do uso do PRF na Implantodontia nos últimos 10 anos. Através de uma revisão de literatura, pretende-se discutir aplicações, vantagens e limitações da técnica, mudanças de protocolo e como podemos incrementar a prática clínica com ganhos teciduais de fato significativos com menor morbidade e menos custos. 


\section{REVISÃO BIBLIOGRÁFICA}

\section{Fibrina rica em plaquetas (PRF)}

A fibrina rica em plaquetas e leucócitos (L-PRF) caracteriza-se pela presença de fatores de crescimentos derivados de plaquetas (PDGF), fator de crescimento endotelial vascular (VEGF), fator de crescimento transformador (TGF), fator de crescimento epidérmico (EGF) incorporados numa complexa matriz de fibrina e pela presença de leucócitos e suas citocinas que possuem ação anti-infecciosa que atuam na modulação imunológica do processo de cicatrização. Possuem também o potencial de estimular angiogênese e proliferação de osteoblastos, além de servir como suporte e atrair células mesenquimais indiferenciadas (CANELLAS JVDS, et al., 2018; FAOT F, et al., 2017; ÖNCU E, et al., 2016). Essa rede complexa obtida durante o processo de polimerização natural da fibrina parece permitir a liberação lenta dos fatores de crescimento durante o processo de reparo da ferida, durante o período de 7 a 14 dias, servindo como um arcabouço para migração e diferenciação celular. (CANELLAS JVDS, et al., 2018)

Inicialmente, o protocolo para obtenção do PRF baseado no tempo e na velocidade de centrifugação foi de $3000 \mathrm{rpm} / 10 \mathrm{~min}$, vem sendo substituído pelo protocolo de $2700 \mathrm{rpm} / 12 \mathrm{~min}$, principalmente, o que resulta em um PRF mais organizado e com membranas mais resistentes que a do protocolo inicial. De uma forma geral, o sangue deve ser coletado antes de iniciar o procedimento cirúrgico, uma vez que a própria cirurgia tende a ativar o processo de coagulação e reparo, o que pode interferir no preparo do L-PRF (AGRAWAL AA, et al., 2017).

Após a centrifugação e finalização da cascata de coagulação, o coágulo obtido passa a poder ser utilizado como plugs a serem colocados em alvéolos, como membranas após compressão manual ou, como é feita mais comumente, através de caixas específicas para o manejo do PRF. Esse coágulo também pode ser cortado e misturado com enxertos ósseos (SHAH R, et al., 2017).

Nos últimos anos, alguns autores alteraram o protocolo de centrifugação diminuindo o tempo e a velocidade de centrifugação, na tentativa de formar uma rede de fibrina com uma distribuição plaquetária mais uniforme e maior concentração de leucócitos, otimizando os fatores de crescimento e resposta celular. Esse conceito deu origem aos chamados PRF avançados (A-PRF e o A-PRF+) que diferem entre si devido ao protocolo de (1500 rpm/ 14 minutos e $1300 \mathrm{rpm} / 8$ minutos, respectivamente). Os autores justificam esses achados devido ao fato de que a alta velocidade de centrifugação tende a empurrar as células, incluindo as plaquetas e leucócitos longe do coágulo. Ao diminuir a velocidade de centrifugação, uma distribuição mais uniforme de plaquetas e um maior número de granulócitos é alcançado. Estes resultados demonstram que 0 uso de baixa velocidade para produzir o PRF otimiza a produção de fatores de crescimento, bem como a resposta celular (SHAH R, et al., 2017; FUJYOKA-KOBAYASHI M, et al., 2017).

Mourão CF et al. (2015) descreveram uma técnica para obter uma forma injetável de PRF chamada i-PRF. Através de uma centrifugação curta durante 2 min a 3300 rpm um fluído amarelado que pode ser injetado ou misturado com enxertos ósseos. Atualmente, uma variedade de enxertos autógenos alógenos, xenógenos e aloplásticos têm sido usados sozinhos ou com diferentes combinações para o aumento do rebordo alveolar. A maioria desses enxertos tem uma natureza osteocondutiva. A adição da fibrina líquida ou do próprio coágulo de PRF aparece como um adjuvante extremamente útil aos enxertos ósseos devido as suas propriedades osteoindutoras (AGRAWAL AA, et al., 2017; SHAH R, et al., 2017; POTRES Z, et al., 2016).

Tunali M, et al. (2014) introduziu uma fibrina rica em plaquetas que é obtida a partir de amostras sanguíneas coletadas em tubos de titânio, daí a sigla T-PRF, ao invés dos convencionais tubos de vidro, com o intuito de aumentar a quantidade de fatores de crescimento formar uma rede de fibrina mais organizada.

\section{Aplicações na implantodontia Osseointegração}

A osseointegração é fundamental para a estabilidade e sucesso dos implantes dentários. Estudos tem focado em reduzir o período da osseointegração diminuindo o período das reabilitações. $O$ tratamento das superfícies dos implantes, o que fez com que esse processo possa ser alcançado em torno de 6 a 8 semanas. 
Uma outra estratégia de acelerar esse processo, consiste em modular o processo de reaparação tecidual, aumentando a formação óssea na região de contato osso-implante após a instalação dos implantes (GERMANIER Y, et al., 2006; ÖNCU E, et al., 2016; SMEETS R, et al., 2016).

Alguns estudos atribuem ao PRF o potencial de acelerar a osseointegração, principalmente durante o período inicial do reparo (ÖNCU E, et al., 2016; TATULLO M, et al., 2012; TABRIZI R, et al., 2017). Diana C et al (2018) encontraram uma alta quantidade de fosfatase alcalina antes do período de degradação do PRF entre $\circ 10^{\circ}$ e o $14^{\circ}$ dia. Além disso, o uso do PRF nas superfícies peri-implantares leva a formação de uma camada de fibrina, favorecendo a adesão plaquetária. Essas situações otimizam a cicatrização peri-implantar.

Diante disso, alguns autores vêm defendendo a possibilidade do PRF acelerar o processo de osseointegração, bem como a possibilidade do aumento da estabilidade primária nas duas primeiras semanas após a instalação dos implantes (DING L, et al., 2019; ÖNCU E, et al., 2016TABRIZI R, et al., 2017; DIANA C, et al., 2018).

\section{Preservação do osso alveolar e os implantes imediatos}

Os protocolos convencionais de instalação estão relacionados com um maior tempo de tratamento, uma vez que o respeito ao período de osseointegração é necessário. Dessa forma, o uso dos implantes imediatos e os protocolos de carga imediata ganharam atenção do ponto de vista científico. Nos implantes imediatos, o preenchimento dos defeitos ósseos com biomaterias tende a aumentar a área de contato osso-implante, favorecendo o processo de osseointegração. Do ponto de vista fisiológico, a manutenção do coágulo pode preencher esses gaps, porém admite-se uma reabsorção do osso alveolar mais acentuada e consequente defeito estético, principalmente em áreas com gaps maiores de 2 mm (ŞIMŞEK S, et al., 2016).

Os implantes imediatos possibilitam uma melhor manutenção dos tecidos peri-implantares. Uma posição adequada da papila associada com uma rápida cicatrização do tecido mole resulta numa menor perda óssea marginal a longo prazo. Diante disso, a colocação dos implantes imediatos permite uma adaptação passiva dos tecidos peri-implantares favorecendo a estética e a saúde dos tecidos peri-implantares (MARRELI M e TATULLO, 2013).

O principal objetivo da preservação do rebordo alveolar é preservar os tecidos duros e moles após as exodontias, facilitando a instalação de implantes em posições mais favoráveis e otimizando as reabilitações orais (STRAUSS FJ, et al., 2018). Plugs de PRF podem ser indicados para o manejo de alvéolos após extrações dentárias para minimizar o processo fisiológico de reabsorção, de forma segura e previsível. (AGRAWAL AA, et al., 2017)

De uma forma geral, o PRF pode ser considerado um material promissor para aumento de rebordos no momento da instalação dos implantes imediatos, desde que seja obtido uma boa estabilidade primária (DIANA C, et al., 2018). Apesar da maioria dos estudos demonstrar que o L-PRF diminui a reabsorção dentária após extrações dentárias quando usado sozinho ou combinado com outros biomateriais (CANELLAS JVDS, et al., 2018), em situações de pobre qualidade óssea, a preservação óssea alveolar seguida pelo protocolo convencional de instalação de implantes deve ser considerada (DIANA C, et al., 2018).

Outro benefício associado ao PRF está relacionado ao reparo de defeitos ósseos peri-implantares (LEE JW, et al., 2012; DING L, et al., 2019). Através de testes biomecânicos, tomográficos e histológicos, estudo recente demonstrou uma maior neoformação óssea na da área de contato osso-implante e reparo quase completo de defeitos ósseos mediante o uso do PRF associado ao uso de células mesenquimais derivadas de adipócitos.

Esses achados corroboram o uso do PRF como um importante aliado nas instalações de implantes imediatos, além do menor custo associado ao uso de biomateriais frequentemente usados nesses casos (LEE JW, et al., 2012; DING L, et al., 2019). Entretanto, vale salientar que estudos envolvendo os eventos biológicos mediados pelo uso do PRF são restritos a defeitos ósseos corticais. A capacidade de reparo grandes defeitos ósseos envolvendo o uso do PRF como único material permanece controverso. (LEE JW, et al., 2012; FAOT F, et al., 2017). 


\section{Levantamento de seio maxilar}

O levantamento do seio maxilar (LSM) consiste em um método previsível para ganho ósseo vertical em região posterior da maxila, que geralmente apresenta uma altura óssea limitada. O osso autógeno é considerado o material "gold standard" para realização desse tipo de procedimento, devido a sua capacidade osteoindutiva e ostecondutiva. Porém a morbidade associada com a cirurgia na área doadora tem incentivado a pesquisa com outros tipos de biomateriais (TAJIMA N, et al., 2013).

Alguns autores sugerem que o uso de substitutos ósseos durante o LSM não é absolutamente necessário, uma vez que o próprio coágulo sanguíneo formado após a elevação da membrana sinusal é capaz de promover formação óssea. Nesse método, o implante é colocado simultaneamente à elevação da membrana, de forma que os próprios implantes funcionem como tendas, e o espaço criado entre a membrana sinusal e o implante é preenchido com sangue. O coágulo formado funciona como um arcabouço, possibilitando a regeneração óssea guiada. Contudo não é sempre que um coágulo sanguíneo estável é conseguido na região. O uso de materiais derivados do sangue, como os concentrados plaquetários e próprio L-PRF, podem ser usados como uma opção viável nessas situações (TAJIMA N, et al., 2013).

O PRF funciona como um coágulo sanguíneo otimizado, o que o torna um importante adjuvante nas técnicas de levantamento de seio maxilar, além de melhorar a regeneração óssea na região entre osso/implante (MAZOR Z, et al., 2009). Quando associados outros biomateriais, a exemplo dos enxertos ósseos particulados, promovem um maior ganho ósseo e uma melhor instalação dos implantes do que nos casos de LSM sem uso de biomaterial (KANAYAMA T, et al., 2016). Ensaios clínicos são necessários para comprovar os benefícios do uso do L-PRF nos LSM em comparação ao coágulo sanguíneo natural.

Por ser um material autógeno, sem custos elevados e de fácil manuseio, vem sendo utilizado nos LSM, tanto nas técnicas através das osteotomias laterais quanto através dos acessos alveolares com os ostéotomos de Summers. Além de proteger a membrana sinusal durante o procedimento, mantem a mesma elevada, possibilitando a formação óssea (KANAYAMA T, et al., 2016). Ambas as técnicas para o levantamento de seio maxilar podem ser realizadas sem o uso de nenhum material, particularmente para espaços de menores volumes. Entretanto, alguns autores acreditam que o ganho ósseo nessas situações é limitado, além da possibilidade da ausência da osseointegração (SUL SH, et al., 2008; SIMONPIERI A, et al., 2011).

Nos LSM com PRF como único biomaterial, maiores benefícios e resultados são encontrados quando associados a instalação simultânea de múltiplos implantes (SIMONPIERI A, et al., 2011; TAJIMA N, et al., 2013). Nesses casos, os implantes funcionam como "parafusos tipo tendas" e mantem a membrana sinusal elevada, o que é fundamental para o sucesso da técnica (SIMONPIERI A, et al., 2011; TAJIMA N, et al., 2013; XUAN F, et al., 2014). Já quando há a associação do PRF com material osteocondutor (Sticky bone), os fatores de crescimento, que são liberados em maior quantidade nos primeiros 7 dias. Ao adicionar os fatores de crescimento, há a potencialização dos potenciais osteogênicos de materiais osteocondutores (JANG ES, et al., 2010). Além disso, há uma menor dispersão do material, o que implica num menor volume de biomaterial necessário para o levantamento de seio e futura colocação de implantes (XUAN, 2014).

Uma preocupação durante a colocação dos implantes no antro do seio maxilar, é o risco de perfuração da membrana sinusal. As membranas de L-PRF podem minimizar esse tipo de risco (KANAYAMA T, et al., 2016). Felizmente, as perfurações da membrana sinusal não parecem estar relacionadas com a sobrevivência dos implantes a longo prazo. Entretanto, as possibilidades de complicações pós-operatórias são mais prováveis de acontecer nos sítios perfurados (TOFFLER M, et al., 2010; ALI S, et al., 2015). O PRF é recomendado para o reparo dessas perfurações por ter uma biocompatibilidade total, tamanho adequado para cobrir as pequenas perfurações, além de possuir um período de reabsorção de 10 a 14 dias (CANELLAS JVDS, et al., 2018).

Considerar uma diminuição de custos nos tratamentos torna alguns tipos de reconstruções complexas, muito pela necessidade do uso de biomateriais como enxertos e membranas biológicas, mais acessíveis a pacientes de baixa renda (GASSLING V, et al., 2013). O efeito do L-PRF nos LSM do seio não mostrou 
vantagem, no quesito ganho ósseo, no entanto admite-se que o período de reparo ósseo pode ser reduzido (STRAUSS FJ, et al., 2018). Porém, o PRF, como material autólogo, pode ser uma alternativa segura e de menor custo ao uso das membranas reabsorvíveis que são normalmente utilizadas nesse tipo de procedimento.

\section{Regeneração de tecidos moles}

Estudos clássicos na literatura atual admitem que a presença de uma mucosa queratinizada (no mínimo 2 $\mathrm{mm}$ ) ao redor de dentes naturais é necessária para a manutenção da saúde gengival. Com relação aos implantes dentários, segue-se o mesmo raciocínio: preservar a saúde dos tecidos moles é um fator importante na prevenção de peri-implantites e sobrevida dos implantes. Atualmente, a técnica preconizada como "padrão-ouro" nos aumentos de tecido mole são os enxertos gengivais livre, porém esse procedimento envolve um grau de morbidade relacionado ao sítio cirúrgico doador, geralmente na região do palato. Muitos estudos têm envolvido o uso das membranas de PRF como alternativas aos enxertos gengivais livres (CHUNG DM, et al., 2006; TEMMERMAN A, et al., 2018).

O emprego do L-PRF está relacionado com aumento da atividade fibroblástica, resultando em uma maior formação de colágeno (GHANAATI S, et al. 2018). Nos protocolos reportados na literatura são observados uma boa regeneração de tecido gengival no pós-operatório, aumento do tecido gengival queratinizado, e consequente ganho estético nos resultados finais das próteses também podem ser observados (AGRAWAL AA, et al., 2017). Pesquisas in vitro tem mostrado um efeito positivo do L-PRF no comportamento celular dos tecidos moles. Este fato encontra-se relacionado com um aumento na proliferação celular envolvida no reparo do tecido mole, bem como o aumento na atividade endotelial e angiogênese (MIRON RJ, et al., 2016).

Em ensaio clínico randomizado comparando o uso do L-PRF com o enxerto gengival livre, técnica preconizada como padrão-ouro para aumento de tecido mole, foi observado ganho de mucosa queratinizada com o uso do PRF, e com uma técnica menos invasiva. Os autores também observaram uma redução nos scores de dor, avaliados através da escala visual analógica, no grupo do PRF. Uma possível explicação para esse fato consiste na não existência do sítio cirúrgico doador, como ocorre nos casos de enxertos gengivais livres. Ademais, os autores chamaram atenção ao uso das membranas do PRF no manejo do sítio cirúrgico doador, geralmente o palato, promovendo uma melhor cicatrização da ferida operatória. Entretanto, é importante avaliar os achados com cautela, visto algumas limitações no estudo, tais quais o curto follow-up, amostra pequena e a ausência da mensuração dos ganhos reais de tecido mole associados ao PRF (TEMMERMAN, et al.,2018).

\section{Aumento do rebordo alveolar}

O aumento do rebordo alveolar é um procedimento comum para corrigir deficiências alveolares antes da colocação dos implantes. Várias técnicas têm sido descritas para reconstruir rebordos alveolares atróficos. Blocos de osso autógeno são mais frequentemente utilizados com o objetivo de ganhos ósseos, sendo considerado o padrão-ouro nesses casos. Todavia, esta técnica é associada com o aumento da morbidade devido a presença de um sítio cirúrgico doador, mas também com a possibilidade de complicações pósoperatória, como por exemplo a reabsorção do enxerto (CORTELLINI, et al., 2018).

A aplicação de técnicas de regeneração óssea guiada, com o objetivo de permitir a instalação de implantes dentários, tem mostrado bons resultados nos aumentos ósseos. O uso da forma líquida do PRF (i-PRF) tem sido proposta para aglutinar o enxerto ósseo particulado, usando o i-PRF na forma do sticky bone (MOURÃO $E F$, et al., 2015). Aumentos verticais em rebordos alveolares com a utilização de membranas reforçadas por titânio e associadas ao uso do L-PRF são métodos previsíveis e seguros, com estudos mostrando boa formação óssea a partir da oitava semana. Estudos também mostram a possibilidade de usar o Sticky bone (PRF aglutinado com osso bovino particulado) associado ao uso das telas de titânio para aumentos tridimensionais do rebordo alveolar (AGRAWAL AA, et al., 2017). Em outro estudo utilizando o sticky bone, os autores concluíram que o PRF pode ser usado de forma segura e efetiva nos aumentos horizontais dos rebordos alveolares com uma média de $4,7 \mathrm{~mm}$ de ganho ósseo (CORTELLINI S, et al., 2018). 
A associação de enxertos ósseos com o L-PRF tem mostrado ganhos ósseos mais expressivos, além de quando associados a enxertos autógenos em bloco, tendem a minimizar o processo de remodelação óssea do enxerto (POTRES Z, et al., 2016; PRIPATNANONT P, et al., 2017). A reabsorção pode acontecer em torno de $50 \%$ dos enxertos em bloco. Os cirurgiões tentam minimizar esse problema adicionando osso bovino particulado ou materiais aloplásticos associados a membranas biológicas, minimizando essa reabsorção. Ensaio clínico avaliando o uso de membranas de PRF associadas a enxertos em bloco removidos do palato, observou que a reabsorção dos enxertos foi estatisticamente menor no grupo teste, que utilizou as barreiras de PRF (MOUSSA M, et al., 2016). Porém, em estudo comparando o uso das membranas de colágeno reabsorvível (BIOGUIDE ${ }^{\circledR}$ ) e membranas de PRF, nas técnicas de regeneração óssea guiada associadas com enxertos em bloco, não houve diferença no quesito sobre ganhos ósseos entre os grupos após 6 meses de acompanhamento (HARTLEV J, 2019).

\section{CONSIDERAÇÕES FINAIS}

Em vários campos da Odontologia, o uso do L-PRF vem crescendo e se tornado cada vez mais popular, principalmente na área da Implantodontia. A literatura admite os benefícios associados ao potencial de acelerar os períodos de cicatrização e na preservação dos rebordos alveolares, facilitando a osseointegração de implantes e possibilitando protocolos de carga precoce em mais pacientes. A efetividade na regeneração de tecidos moles e no controle da dor ainda permanece incerta. Os estudos são promissores e apontam para avanços e ganhos nas regenerações teciduais apesar da necessidade de mais ensaios clínicos.

\section{REFERÊNCIAS}

1. AGRAWAL AA. Evolution, current status and advances in application of platelet concentrate in periodontics and implantology. World J Clin Cases. 2017 May 16;5(5):159-171.

2. ALI S, et al. Platelet-Rich Fibrin in Maxillary Sinus Augmentation: A Systematic Review. J Oral Implantol. 2015 Dec;41(6):746-53.

3. CANELLAS JVDS, et al. Evaluation of postoperative complications after mandibular third molar surgery with the use of platelet-rich fibrin: a systematic review and meta-analysis. Int J Oral Maxillofac Surg. 2017 Sep;46(9):1138-1146.

4. CHENCHEV IL, et al. Application of Platelet-Rich Fibrin and Injectable Platelet-Rich Fibrin in Combination of Bone Substitute Material for Alveolar Ridge Augmentation - a Case Report. Folia Med (Plovdiv). 2017 Sep 1;59 (3):362366.

5. CHUNG DM, et al. Significance of keratinized mucosa in maintenance of dental implants with different surfaces. $J$ Periodontol. 2006; 77:1410-1420.

6. CORTELLINI S, et al. Leucocyte-and pletelet-rich fibrin block for bone augmentation procedure: a proof of concept study. J Clin Periodontol. 2018 May;45(5):624-634.

7. DIANA C, et al. Mohanty S, Chaudhary Z, Kumari S, Dabas J, Bodh R. Does platelet-rich fibrin have a role in osseointegration of immediate implants? A randomized, singleblind, controlled clinical trial. Int J Oral Maxillofac Surg. 2018 Sep;47(9):1178-1188.

8. DING L, et al. Bone Regeneration of Canine Peri-implant Defects Using Cell Sheets of Adipose-Derived Mesenchymal Stem Cells and Platelet-Rich Fibrin Membranes. J Oral Maxillofac Surg. 2019 Mar;77(3):499-514.

9. FAOT F, et al. The effect of L-PRF membranes on bone healings in rabbit tibiae bone defects: microCT and biomarker results. Sci Rep. 2017 Apr 12;7:46452.

10. FUJIOKA-KOBAYASHI M, et al. Optimized platelet-rich fibrin with the low-speed concept: growth factor release, biocompatibility, and cellular response. J Periodontol 2017 Jan;88(1):112-121.

11. GASSLING V, et al. Comparison of two different absorbable membranes for the coverage of lateral osteotomy sites in maxillary sinus augmentation: A preliminary study. J Craniomaxillofac Surg. 2013 Jan;41(1):76-82.

12. GERMANIER Y, et al. Enhanced bone apposition around biofunctionalized sandblasted and acidetched titanium implant surfaces. A histomorphometric study in miniature pigs. Clin Oral Implants Res. 2006; 17:251-7

13. GHANAATI S, et al. Fifteen years of platelet rich fibrin in dentistry and oromaxillofacial surgery: how high is the level of scientific evidence? J Oral Implantol. 2018 Dec;44(6):471-492.

14. HARTLEV J, et al. Cone beam computed tomography evaluation of staged lateral ridge augmentation using plateletrich fibrin or resorbable collagen membranes in a randomized controlled clinical trial. Clin Oral Implants Res. 2019 Mar;30(3):277-284. 
15. JANG ES, et al. Restoration of a peri-ímplant defects in immediate implant installations by Choukroun platelet-rich fibrin and silk fibroin powder combination graft. Oral Surg Oral Med Oral Pathol Oral Radiol Endod. 2010 Jun;109(6):831-6.

16. KANAYAMA T, et al. Crestal approach to sinus floor elevation for atrophic maxilla using platelet-rich fibrin as the only grafting material: a 1 year prospective study. Implant Dent. 2016 Feb; 25(1):32-8.

17. LEE JW, et al. Restoration of a peri-ímplant defect by platelet rich fibrin. Oral Surg Oral Med Oral Pathol Oral Radiol. 2012;113(4):459-63.

18. MARRELLI $M$ e TATULLO $M$. Influence of PRF in the healing of bone and gingival tissues. Clinical and histological evaluations. Eur Rev Med Pharmacol Sci. 2013 Jul;17(14):1958-62.

19. MAZOR Z, ET AL. Sinus floor augmentation with simultaneous implant placement using Choukroun's platelet-rich fibrin as the sole grafting material: a radiologic and histologic study at 6 months. J Periodontol. 2009 Dec;80(12):205664.

20. MIRON RJ, ET AL. Platelet-rich fibrin and soft tissue wound healing: a systematic review. Tissue Eng Part B Rev. 2017 Feb;23(1):83-99. DOI: 10.1089/ten.TEB.2016.0233.

21. MOURÃO CF, et al. Obtention of injectable platelets rich-fibrin (i-PRF) and its polymerization with bone graft: technical note. Rev Col Bras Cir 2015; 42: 421-423.

22. MOUSSA M, et al. Anterior maxilla augumentation using palatal bone block with platelet-rich fibrin: a controlled trial. Int J Oral Maxillofac Implants. 2016 May-Jun;31(3):708-15. DOI: 10.11607/jomi.3926.

23. ÖNCÜ E, et al. Posıtıve effect of platelet rich fibrin on osseointegration. Med Oral Patol Oral Cir Bucal. 2016 Sep 1; 21(5): e601-7.

24. POTRES Z, et al. Assisted Wound Healing and Vertical Bone Regeneration with Simultaneous Implant Placement: A Histologic Pilot Study. Int J Oral Maxillofac Implants. 2016 Jan-Feb;31(1):45-54.

25. PRIPATNANONT $P$, et al. Dimensional change and microstructure of intraoral bone block grafts covered with plateletrich fibrinand a barrier membrane in ridge augumentation: a pilot investigation. Int $\mathrm{J}$ Periodontics Restorative Dent. 2017 Sep/Oct;37(5):693-703.

26. SHAH R, et al. An update on the protocols and biologic actions of Platelet Rich Fibrin in Dentistry. Eur J Prosthodont Restor Dent. 2017 Jun;25(2):64-72.

27. SIMONPIERI A, et al. Simultaneous sinus lift and implantation using microthreaded implants and leukocyte-and platelet-rich fibrin as sole grafting material: a six year experience. Implant Dent. 2011 Feb;20(1):2-12.

28. ŞIMŞEK S, et al. Histomorphometric Evaluation of Bone Formation in Peri-Implant Defects Treated With Different Regeneration Techniques: AnExperimental Study in a Rabbit Model. J Oral Maxillofac Surg. 2016 Sep;74(9):175764.

29. SMEETS R, et al. Impact of Dental Implant Surface Modifications on Osseointegration. Biomed Res Int. 2016; 2016 : 6285620.

30. STRAUSS FJ, et al. The use of platelet-rich fibrin to enhance the outcomes of implant therapy: A systematic review. Clin Oral Implants Res. 2018 Oct;29 Suppl 18:6-19.

31. SUL SH, et al. Effects of sinus membrane elevation on bone formation around implants placed in the maxillary sinus cavity: An experimental study. Oral Surg Oral Med Oral Pathol Oral Radiol Endod. 2008; 105:684-687.

32. TABRIZI R, et al. Does platelet-rich fibrin increase the stability of implants in the posterior of the maxilla? A splitmouth randomized clinical trial. Int J Oral Maxillofac Surg. 2018 May;47(5):672-675.

33. TAJIMA N, et al. Evaluation of sinus floor augmentation with simultaneous implant placement using platelet-rich fibrin as sole grafing material. Int J Oral Maxillofac Implants. 2013 Jan-Feb;28(1):77-83.

34. TATULLO $\mathrm{M}$, et al. Platelet rich fibrin (PRF) in reconstructive surgery of atrophied maxillary bones: clinical and histological evaluations. Int J Med Sci. 2012;9(10):872-80.

35. TEMMERMAN A, et al. L-PRF for increasing the width of keratinized mucosa around implants: A split-mouth, randomized, controlled pilot clinical trial. J Periodontal Res. 2018 Oct;53(5):793-800.

36. TOFFLER $\mathrm{M}$, et al. Osteotome-mediated sinus floor elevation using only platelet-rich fibrin: an early report on 110 patients. Implant Dent 2010 Oct;19(5):447-56.

37. TUNALI M, et al. A novel platelet concentrate: titanium-prepared platelet-rich fibrin. Biomed Res Int $2014 ; 209548$.

38. XUAN F, et al. A comparative study of the regenerative effect of sinus bone grafting with platelet-rich fibrin mixed BioOss $\AA$ and commercial fibrin mixed Bio-Oss $\AA$ : an experimental study. J Craniomaxillofac Surg. 2014 Jun;42(4):e4750 . 